\title{
Pore Structure Characterization of Supported Polycrystalline Zeolite Membranes by Positron Annihilation Spectroscopy
}

\author{
Xiaoli Ma ${ }^{\mathrm{a}}$, Huan Wang ${ }^{\mathrm{b}}$, Haibing Wang ${ }^{\mathrm{a}}$, Jessica O’Brien-Abraham ${ }^{\mathrm{a}}$, and Y.S. Lin ${ }^{\mathrm{a}, *}$ \\ a- School for Engineering of Matter, Transport and Energy, Arizona State University, Tempe, \\ Arizona 85287, USA \\ b- Department of Chemical and Biomolecular Engineering, National University of Singapore, \\ 4 Engineering Drive 4, Singapore 117576, Singapore
}

\begin{abstract}
Characterizing the pore structure of supported polycrystalline zeolite membranes is important but has remained a major challenge in studying microporous inorganic membranes. This paper reports the use of positron annihilation spectroscopy including positron annihilation lifetime spectroscopy and Doppler broadening energy spectroscopy to non-destructively characterize the pore structure of four MFI zeolite membranes of different microstructure on alumina supports. Positron annihilation lifetime spectroscopy analysis reveals a bimodal pore structure consisting of intracrystalline zeolitic micropores of around $0.6 \mathrm{~nm}$ in diameter and irregular intercrystalline micropores of 1.4 to $1.8 \mathrm{~nm}$ in size for the four MFI zeolite membranes studied. Distributions of the micropores along the membrane thickness direction can be inferred from Doppler broadening energy spectroscopy results, illustrating development of intercrystalline gaps during the growth of the zeolite layer. The amount and size of the intercrystalline micropores of the zeolite membranes vary with the synthesis method, and are the smallest for the randomly oriented MFI zeolite membrane synthesized without template and largest for the $c$-oriented MFI zeolite membrane synthesized with template. The $c$-oriented membrane has an asymmetric distribution of intercrystalline pores along the film growth direction as compared to the uniform distribution of the bimodal structure for the other three membranes. The pore structure data obtained by positron annihilation spectroscopy are consistent with the xylene isomer separation performance of these membranes.
\end{abstract}

Keywords: zeolite membranes, intercrystalline micropores, membrane synthesis, microstructure characterization, structure-property relationship 
* Correspondence author- Email: Jerry.Lin@,ASU.edu

\section{Introduction}

Polycrystalline zeolite membranes offer many attractive properties, such as excellent separation capability and high structural stability, for separation and catalytic membrane reactor applications [1-3]. The separation properties and stability of the zeolite membranes are derived from their unique crystalline pore structure, pore surface chemistry and bulk inorganic material characteristics [4-6]. However, polycrystalline zeolite membranes contain grain-boundary or intercrystalline gaps, which, if larger than the zeolitic pores, provide nonselective pathways for mass transport, degrading the overall performance of the membrane $[7,8]$. Researchers have tried to minimize or eliminate these intercrystalline defects through manipulation of crystal orientation [9], template-free secondary growth [10], template removal by rapid calcination [11], and post-synthesis defect repairing [12]. It is expected that the intercrystalline pore structure of the polycrystalline zeolite membrane depends on the synthesis methods, so a good understanding of the microstructure of polycrystalline zeolite membrane is key to ensure synthesis of high quality zeolite membranes. However, it is difficult to directly characterize the intercrystalline gaps of supported zeolite membranes, and the effectiveness of a synthesis or post-treatment method to prepare zeolite membranes with intercrystalline pores minimized or eliminated. As a result, the research on synthesis of high quality zeolite membranes was largely performed in try-and-error fashion.

Direct observation of the complex hierarchical microporous structure of polycrystalline zeolite membranes remains a major challenge in the membrane community, because the intercrystalline pores are in micropore range $(<2 \mathrm{~nm})$ and of highly irregular topologic structure [13]. Nitrogen adsorption porosimetry is a destructive means to characterize the pore structure of zeolite membranes by measuring the powdery samples of the zeolite membrane layer scratched off from the support [14]. Permporometry uses condensable gas like water or hexane in the process, both of which could induce microstructure change by strong adsorption and affect the measurement accuracy [15]. Molecular probing method relies on the permeance cutoff of a series of probing gases (or liquids) with different molecular sizes to estimate the critical pore size of the membrane [16]. All these methods could not provide information of the hierarchical pore structure of the supported polycrystalline zeolite membranes.

Positron annihilation spectroscopy (PAS), based principally on the annihilation phenomena of positron and positronium due to pickoff in open-volume defects, is an emerging nondestructive technique to probe the pore structure of various materials [17]. 
Among the many PAS techniques, positron annihilation lifetime spectroscopy (PALS) has proven to be effective in quantifying the free-volume in polymers $[18,19]$, micro/meso pores in silica [20], and cage and cavity size in zeolite crystals [21,22]. Recently, Yan and coworkers reported using PALS to obtain pore size and pore connectivity information in zeolite low-k films [23]. Duke and co-workers reported the use of PALS to characterize the pore structure of MFI zeolite powders [24,25]. The results revealed a hierarchical trimodal porous structure of the MFI zeolite powders containing intrinsic zeolite crystalline pores, intercrystalline micropores and interparticle mesopores [24,25]. The work shows promise of using the PAS technique to study pore structure of supported zeolite membranes.

In this paper, we report, for the first time, the use of two PAS techniques, PALS and Doppler broadening energy spectroscopy (DBES), to characterize non-destructively the hierarchical microporous structure of polycrystalline zeolite membranes on inorganic supports. The membrane model system chosen in our study is MFI type zeolite membrane, one of the most studied zeolite membranes in the literature because of its industrial importance. DBES was used to detect the free-volume variation and the multilayer structure of composite polymer membranes [26-28], but it has never been used to characterize zeolite membranes. Such structure information is important to guide the membrane synthesis and to explain the separation performance of the zeolite membranes. The objectives of this paper are to demonstrate that PALS and DBES are effective in revealing the complex hierarchical structure of zeolite membranes composed of both intra and intercrystalline micropores and use of these techniques to help determine synthesis-structure-properties relationship of polycrystalline zeolite membranes.

\section{Experimental}

\subsection{Membrane synthesis and characterization}

The following four supported MFI zeolite membranes of different microstructure, as summarized in Table 1 , were synthesized on macroporous $\alpha$-alumina support by the seeded secondary growth methods under different conditions as reported in the respective literature: (a) randomly oriented MFI zeolite membrane (TR) prepared with the use of a TPABr template in the secondary growth step [29]; (b) randomly oriented MFI zeolite membrane (TFR) prepared without an organic template in the secondary growth step (template-free method) [30]; (c) h0h-oriented MFI zeolite membrane (TH) prepared with a template by performing sequential secondary growth at a moderate temperature of $130{ }^{\circ} \mathrm{C}[31]$; and (d) $c$ - 
oriented MFI zeolite membrane (TC) prepared with a template at a high secondary growth temperature of $175^{\circ} \mathrm{C}[32]$.

The disk supports were pressed from A16 powders (Almatis), and then sintered at $1150{ }^{\circ} \mathrm{C}$ for $30 \mathrm{~h}$ in air. One side of the disk was polished using SiC sandpaper (\#500, \#800 and \#1200) to smooth the surface. Silicalite seeds were prepared by hydrothermal synthesis at $120{ }^{\circ} \mathrm{C}$ for $12 \mathrm{~h}$ using a synthesis solution of $10 \mathrm{SiO}_{2}: 2.4 \mathrm{TPAOH}: 1 \mathrm{NaOH}: 110 \mathrm{H}_{2} \mathrm{O}$. Silicalite seeds layer were dip-coated onto the polished side of $\alpha$-alumina supports, dried in humid oven at $40{ }^{\circ} \mathrm{C}$ for 2 days and then calcined at $550{ }^{\circ} \mathrm{C}$ in air for $8 \mathrm{~h}$ to strengthen the bonding between seeds layer and support.

The secondary growth solution for three templated membranes had a molar composition of $1 \mathrm{KOH}: 1 \mathrm{TPABr}: 4.5 \mathrm{SiO}_{2}: 16 \mathrm{C}_{2} \mathrm{H}_{5} \mathrm{O}: 1000 \mathrm{H}_{2} \mathrm{O}$. The composition of the synthesis solution for template-free secondary growth was $5 \mathrm{~g} \mathrm{SiO}_{2}: 60 \mathrm{~g} \mathrm{H}_{2} \mathrm{O}: 1.15 \mathrm{~g} \mathrm{NaOH}$ : $0.65 \mathrm{~g} \mathrm{Al}_{2}\left(\mathrm{SO}_{4}\right)_{3} \cdot 18 \mathrm{H}_{2} \mathrm{O}$. The solution and seeded supports were transferred to a Teflon-lined stainless steel autoclave and hydrothermally treated at different conditions as listed in Table 1. After synthesis, the membranes were washed with de-ionized water for several times and dried at room temperature for one day. The TR, TH, TC membranes synthesized using templated method were calcined at $550{ }^{\circ} \mathrm{C}$ in air for $8 \mathrm{~h}$ to remove the templates trapped inside zeolite pores. The template-free synthesized membrane (TFR) was dried at $200{ }^{\circ} \mathrm{C}$ for $8 \mathrm{~h}$ to remove any adsorbed water and other impurities in the membranes.

The surface and cross-section of the membranes were characterized by scanning electron microscopy (SEM) (Philips, XL 30) to evaluate the morphology and to estimate the thickness of the membranes. X-ray diffraction (XRD) (Bruker AXS-D8, Cu Ka radiation) was used to analyze the crystal structure, especially the orientation of the membranes.

\subsection{Membrane separation performance measurement}

The xylene isomers separation performance was measured using a home-made pervaporation setup [13]. The MFI zeolite membrane was placed in the stainless steel pervaporation cell with the membrane layer facing up to the feed reservoir, which was filled with pure $p$-xylene (99\%, Sigma-Aldrich) or $o$-xylene (99\%, Sigma-Aldrich). The permeate side or downstream side was evacuated by a vacuum pump, and the permeated vapors were collected by a cold trap placing in liquid nitrogen. The duration of each run was kept at $4 \mathrm{~h}$. The flux of each component was calculated by Equation 1,

$$
J=\frac{w}{A t}
$$


where $w$ is the weight of collected sample $(\mathrm{kg}), A$ is the permeation area $\left(\mathrm{m}^{2}\right), t$ is the total time for the run (hr). The ideal selectivity was determined by the ratio of the $p$-xylene flux to the $o$-xylene flux.

\subsection{Positron annihilation spectroscopy}

Two PAS techniques, positron annihilation lifetime spectrocopy (PALS) and Doppler broadening energy spectroscopy (DBES), were conducted by using a PAS coupled with a variable monoenergetic positron slow beam. The detailed description of the experimental set up can be found in literature [28]. The surface of zeolite film of each of the four supported zeolite membranes was subjected to positron irradiation, as illustrated in Figure 1. The PALS measures the pore size and the distribution at a certain depth, while the DBES qualitatively examines the pore profiles as a function of depth from the membrane surface. Both of them were conducted under a vacuum level lower than $10^{-6}$ torr. The PALS measurements were carried out at fixed incident energy of $5 \mathrm{keV}$ with a counting rate of $50 \mathrm{cps}$ for each membrane. This corresponds to a mean depth of around $0.49 \mu \mathrm{m}$ in the membrane. In the measurement, the secondary electrons emitted from the membrane surface detected by the multichannel plate (MCP) were taken as the start signal while the photons detected by a $\mathrm{BaF}_{2}$ detector were the stop signal. The PALS spectra were obtained by counting the coincident events of the two signals.

The obtained raw PALS spectrum was analyzed by both the program MELT based on a continuous decay function and the program PATFIT which carries out the finite analysis by a discrete function [33]. MELT usually shows information about the pore size and its distribution, and PATFIT provides the details about the average lifetime for the pick-off ortho-positronium (o-Ps) $\left(\tau_{3}\right)$ and its intensity $\left(\mathrm{I}_{3}\right)$. The mean pore radius is correlated to $\tau_{3}$ by the semi-empirical equation as shown in Equation 2.

$$
\tau_{3}=\frac{1}{2}\left[1-\left(\frac{R}{R+\Delta R}\right)+\frac{1}{2 \pi} \sin \left(\frac{2 \pi R}{R+\Delta R}\right)\right]^{-1}
$$

where $R$ is the pore radius and $\Delta R$ is an empirical parameter determined by calibration on materials with known free volume sizes. $1.656 \AA$ was used for $\Delta R$ in this work [34]. This equation was reported to be valid for $o$-Ps lifetime smaller than $\sim 20 \mathrm{~ns}$ or pore radius smaller than $1 \mathrm{~nm}$ [35].

For DBES, a total of 29 spectra measured at different positron incident energies in the range of 0.1 to $27 \mathrm{keV}$ were recorded by a HP Ge solid-state detector for a sample membrane. 
Each spectrum carried 1 million counts with a counting rate of 800-1000 cps. The incident energy of the slow positron beam $\left(E_{+}\right)$is correlated to the positron penetration depth in a membrane $(Z)$ by Equation $3[26,36]$ :

$$
Z=\frac{40}{\rho} \times E_{+}^{1.6}
$$

where $Z$ is in nm, $E_{+}$is in $\mathrm{keV}$ and $\rho$ refers the density of the film $\left(1 \mathrm{~g} / \mathrm{cm}^{3}\right.$ was used in this work). As indicated, the positron could penetrate into the membrane at different depths by varying $E_{+}$. Therefore, the depth profile of the pores in the membrane as a function of depth is investigated by DBES analyses. Three parameters, S, W and R were collected from DBES. The detailed definitions and descriptions of these parameters can be found in other references [26].

\section{Results and discussion}

\subsection{Membrane Morphology and PALS Characterization Results}

The structure, orientation and morphology of the four zeolite membranes were examined by the surface and cross-sectional SEM images and XRD patterns given in Figure 2 and Figure 3, respectively. The SEM images in Figure 2 show that these membranes, with a thickness of 5 to $15 \mu \mathrm{m}$, are of high integrity and contain no surface macroscopic defects. XRD patterns in Figure 3 confirm random orientation for the TR and TFR membranes, $h 0 h$ orientation for the TH membrane and $c$-orientation for the TC membrane. These data of morphology and crystal structure and orientation of the MFI membranes are consistent with those reported in the literature [29-32].

In PAS measurements, the positronium with a Bohr radius of $0.53 \AA$ was able to access all pore spaces in the zeolite layer without altering the pore structure. In this work, PALS measured the pores at a mean depth of $0.49 \mu \mathrm{m}$ from the surface of the zeolite membrane. The collected positron annihilation lifetime spectra are shown in Figure 4. These spectra were best fitted with four discrete lifetime components based on PATFIT program. The third lifetime $\tau_{3}$ and the fourth lifetime $\tau_{4}$ are on the order of a few ns and are due to ortho-positroniums (o-Ps) annihilation by pickoff inside the pores. Assuming the pores are of spherical shape, the calculated pore sizes from $\tau_{3}$ and $\tau_{4}$ are in the micropores range. It should be noted that five lifetime components were reported to be the best fit for PAL spectra of zeolite powders $[24,25]$, with the fifth long lifetime ( $>50 \mathrm{~ns}$ ) suggesting the existence of 
mesopores between zeolite particles. Our PAL results here clearly show that for a high quality zeolite membrane, the pore structure is composed of bimodal micropores with the absence of any mesopores.

Table 2 shows the average values for $\tau_{3}, \tau_{4}$ and their respective intensities $\mathrm{I}_{3}, \mathrm{I}_{4}$ based on the PATFIT program, as well as the calculated pore radius $(\mathrm{R})$ and pore volume fractions. The smaller pores calculated from $\tau_{3}$ have a pore radius ranging from 2.7 to $3.6 \AA$, which agree well with the crystallographically defined MFI zeolitic pore size of $0.55 \mathrm{~nm}$ (pore radius of about $2.8 \AA$ ). These are intracrystalline zeolitic micropores in the membranes. The slightly larger value for the pore size measured from PAL is probably due to assumption of the sphere shape for the pores in the model, which also accounts the presence of channel intersections. Similar finding was reported for the pore size analysis on different types of zeolite crystals using PAL [37]. On the other hand, the larger pores with radius in $7.43 \AA$ $9.17 \AA$ are found for all four MFI zeolite membranes, and these pores most likely belong to the intercrystalline micropores. The fractions of intra and intercrystalline pores can be represented from $I_{3} /\left(I_{3}+I_{4}\right)$ and $I_{4} /\left(I_{3}+I_{4}\right)$ for each membrane, as shown in Table 2 . It can be seen that for the two randomly and the $h 0 h$ - oriented zeolite membranes, the intrinsic zeolitic pores contribute to above $90 \%$ of the total pore volume. However, the $c$-oriented zeolite membranes contains much less intrinsic pores. This will be discussed next with the DBES results.

Figure 5 shows the lifetime distribution curves obtained by MELT program for the four membranes. As shown, the larger intercrystalline pores are much more broadly distributed than the intracrystalline pores, which is consistent with the highly irregular topologic structure of the intercrystalline micropores and the well-defined nature of zeolitic pores.

The results of PAL analysis show that intercrystalline pores are different in size and quantity for these zeolite membranes of different structure synthesized under different conditions. The template-free, randomly oriented membrane contains intercrystalline micropores with smaller size (7.43 $\AA$ ) and lowest amount $(4.6 \%)$, confirming the advantage of template free synthesis method in minimizing the intercrystalline pores of the zeolite membranes $[10,38]$. It was suggested that removing templates from zeolitic pores by high temperature calcination $\left(>500^{\circ} \mathrm{C}\right)$ creates and/or enlarges the intercrystalline gaps due to the shrinkage in zeolite framework [39]. On the other hand, the c-oriented MFI zeolite membrane (TC membrane) contains smaller measured intracystalline pores $(2.73 \AA)$, but bigger intercrystalline pores $(9.17 \AA)$ in larger pore fraction $(53.3 \%)$ than the other three 
membranes. We hypothesize that the differences in intracrystalline pore sizes for the four membranes may be caused by the asymmetric intracrystalline pore structure of MFI-type zeolites. The pore structure of MFI zeolite consists of two channels: a straight channel along the $b$-axis with circular openings of $0.54 \times 0.56 \mathrm{~nm}$ and a sinusoidal channel along the $a$-axis with elliptical openings of $0.51 \times 0.55 \mathrm{~nm}$. Along $c$-direction, which is the channel intersections, the molecules will diffuse through either the straight channel and/or the sinusoidal channel. And the Ps will probably take the same tortuous path during their transport through the $c$-oriented membrane. In this case, the empirical equation which assumes the pores are of spherical in shape may be not as accurate for $c$-oriented membrane as for the other membranes. This may be responsible for the larger intercrystalline pores obtained for the $c$-oriented MFI zeolite membrane.

\subsection{Membrane structure by DBES analysis and separation performance}

The DBES analysis was performed on these zeolite membranes as a function of the incident energy, and S, R and W parameters were collected to give the pore structure distribution along the direction normal to the membrane surface ( $\mathrm{z}$ direction shown in Figure 1). According to the use of DBES for characterizing polymer membranes [26,27], $\mathrm{S}$ parameters are associated with the Ps pick-off annihilation in free volumes ( $\AA$ to $\mathrm{nm}$ ), while $\mathrm{R}$ parameters are related to the existence of large pores ( $\mathrm{nm}$ to $\mu \mathrm{m})$. The pores in the four zeolite membranes can be divided into three groups: (1) intracrystalline pores; (2) intercrystalline pores with radius smaller than $1 \mathrm{~nm}$ and (3) intercrystalline pores with radius larger than $1 \mathrm{~nm}$. Therefore, we believe $\mathrm{S}$ parameter is a combination of pores from group (1) and (2), while $\mathrm{R}$ parameter is associated with group 3 pores. The $\mathrm{S}$ and $\mathrm{R}$ parameters versus incident energy (or the depth from the zeolite membrane surface) for the four membranes are shown in Figure $6 \mathrm{a}$ and $6 \mathrm{~b}$. Considering that all these membranes possess similar intracrystalline pores, the $\mathrm{S}$ parameter results show that the intercrystalline pores with radius smaller than $1 \mathrm{~nm}$ in the zeolite membrane layer for the four membranes decreases in the order: $\mathrm{TC}>\mathrm{TH}>\mathrm{TR}>\mathrm{TFR}$. This agrees well with the order of intercrystalline pore fractions (in Table 2) from PALS which measured the pores at a mean depth of $0.49 \mu \mathrm{m}$.

The results of $\mathrm{R}$ parameters show that the TC membrane has much more intercrystalline pores with radius larger than $1 \mathrm{~nm}$ than the other three membranes. This explains the much larger fraction of the intercrystalline pores for the TC membrane measured by the PALS as compared to the other three membranes. Furthermore, for the TC membrane the amount of these larger intercrystalline pore increases from the zeolite membrane surface 
towards the zeolite/support interface. This is consistent with the columnar microstructure for the TC membrane observed by SEM, as discussed above. W parameter shown in Figure 7a can provide information about the type of chemical environment where the positron annihilation takes place [26,27]. Only one slope was observed for the W vs S parameters shown in Figure $7 \mathrm{~b}$, indicating no changes of chemical composition or void type in the four membranes along the membrane thickness direction.

The structures of these four MFI zeolite membranes identified by PAS are schematically represented in Figure 8 . The specific microporous features can be correlated to the xylene separation properties of the membranes. Table 3 shows the performance of xylene isomers pervaporation of the four MFI-zeolite membranes prepared in this work. The template-free membrane (TFR) exhibits highest p/o-xylene ideal selectivity of 24 , about $6 \sim 13$ times higher than the other three membranes synthesized with the template. This can be explained by the more desirable microstructure of TFR membrane as examined from our PAS analysis. The intracrystalline pores for the four studied membranes are of around $0.6 \mathrm{~nm}$ in diameter, and is selective to $p$-xylene (kinetic diameter $\sim 0.58 \mathrm{~nm}$ ) over the bulkier $o$-xylene $(\sim 0.68 \mathrm{~nm})$ through molecular sieving effect. However, diffusion of $p$ - and $o$-xylene through the relatively large intercrystalline pores $(1.4-1.8 \mathrm{~nm})$ follows Knudsen-like diffusion mechanism, which is not selective to molecules with the same molecular weight. The template-free MFI zeolite membrane contains intercrystalline micropores in smaller size and lower quantity than the other three MFI zeolite membranes. Hence a better overall separation performance is achieved for the TFR membrane due to the less non-selective flow from the intercrystalline pores.

\section{Conclusions}

The work demonstrated that PAS techniques, including PALS and DBES, are effective non-destructive methods to characterize the pore structure of supported polycrystalline zeolite membranes. The MFI zeolite membranes feature a bimodal pore structure consisting of intracrystalline zeolitic micropores of around $0.6 \mathrm{~nm}$ in diameter and irregular intercrystalline micropores of 1.4 to $1.8 \mathrm{~nm}$ in size. The quantity and size of the intercrystalline pores and their distribution along the membrane thickness of the zeolite membranes are determined by the synthesis conditions including the usage of template which give MFI zeolite of different crystal orientation. The quantity and size of the intercrystalline

pores are largest for the $c$-oriented membrane and smallest for the template free random oriented membrane, consistent with the xylene separation results. PAS results provide 
distribution of the bimodal pores along the membrane growth direction. The $c$-oriented MFI zeolite has asymmetric structure with the amount of intercrytalline pores increasing from the zeolite membrane surface towards the zeolite-support interface.

\section{Acknowledgements}

The authors would like to acknowledge the support of the U. S. Department of Energy (DE-PS36-03GO93007) and China Electrical Power Research Institute on the work. Special thanks go to Prof. Neal T.S. Chung of National University of Singapore for his support on the collaborative effort. 


\section{References}

[1] A. Tavolaro, E. Drioli, Zeolite membranes, Adv. Mater. 11 (1999) 975-996.

[2] J. Caro, M. Noack, Zeolite membranes-Recent developments and progress, Micropor. Mesopor. Mat. 115 (2008) 215-233.

[3] Y.S. Lin, M.C. Duke, Recent progress in polycrystalline zeolite membrane research, Curr. Opin.Chem. Eng. 2 (2013) 209-216.

[4] J. Caro, M. Noack, P. Kölsch, R. Schäfer, Zeolite membranes-state of their development and perspective, Micropor. Mesopor. Mater. 38 (2000) 3-24.

[5] J. Gascon, F. Kapteijn, B. Zornoza, V. Sebastián, C. Casado, J. Coronas, Practical approach to zeolitic membranes and coatings: State of the art, opportunities, barriers, and future perspectives, Chem. Mater. 24 (2012) 2829-2844.

[6] T.C. Bowen, R.D. Noble, J.L. Falconer, Fundamentals and applications of pervaporation through zeolite membranes, J. Membr. Sci. 245 (2004) 1-33.

[7] X.C. Xu, W.S. Yang, J. Liu, L.W. Lin, Synthesis of a high-permeance NaA zeolite membrane by microwave heating, Adv. Mater. 12 (2000) 195-198.

[8] D. Korelskiy, P.C. Ye, H. Zhou, J. Mouzon, J. Hedlund, Micropor. Mesopor. Mater. An experimental study of micropore defects in MFI membranes, 186 (2014) 194-200.

[9] Z.P. Lai, M. Tsapatsis, J.P. Nicolich, Siliceous ZSM-5 membranes by secondary growth of b-oriented seed layers, Adv. Funct. Mater, 14 (2004) 716-729.

[10] M. Pan, Y.S. Lin, Template-free secondary growth synthesis of MFI type zeolite membranes, Micropor. Mesopor. Mater. 43 (2001) 319-327.

[11] J. Choi, H.K. Jeong, M.A. Snyder, J.A. Stoeger, R.I. Masel, M. Tsapatsis, Grain boundary defect elimination in a zeolite membrane by rapid thermal processing, Science 325 (2009) 590-593.

[12] Z. Hong, C. Zhang, X.H. Gu, W.Q. Jin, N.P. Xu, A simple method for healing nonzeolitic pores of MFI membranes by hydrolysis of silanes, J. Membr. Sci. 366 (2011) 427-435.

[13] K. Wegner, J.H. Dong, Y.S. Lin, Polycrystalline MFI zeolite membranes: xylene pervaporation and its implication on membrane microstructure, J. Membr. Sci. 158 (1999) 17-27.

[14] T. Sano, M. Hasegawa, Y. Kawakami, Y. Kiyozumi, H. Yanagishita, D. Kitamoto, F. Mizukami, Potentials of silicalite membranes for the separation of alcohol-water mixtures, Stud. Surf. Sci. Catal. 84 (1994) 1175-1182. 
[15] M. Noack, G.T.P. Mabande, J. Caro, G. Georgi, W. Schwieger, P. Kölsch, A. Avhale, Influence of $\mathrm{Si} / \mathrm{Al}$ ratio, pre-treatment and measurement conditions on permeation properties of MFI membranes on metallic and ceramic supports, Micropor. Mesopor. Mater. 82 (2005) 147-157.

[16] J. Hedlund, M. Noack, P. Kölsch, D. Creaser, J. Caro, J. Sterte. ZSM-5 membranes synthesized without organic templates using a seeding technique, J. Membr. Sci. 159 (1999) 263-273.

[17] D.W. Gidley, H.-G. Peng, R.S. Valley, Positron annihilation as a method to characterize porous materials, Annu. Rev. Mater. Res. 36 (2006) 49-79.

[18] G.M. Geise, C.M. Doherty, A.J. Hill, B.D. Freeman, D.R. Paul, Free volume characterization of sulfonated styrenic pentablock copolymers using positron annihilation lifetime spectroscopy, J. Membr. Sci. 453 (2014) 425-434.

[19] H. Wang, S.L. Liu, T.S. Chung, H.M. Chen, Y.C. Jean, K.P. Pramoda, The evolution of poly(hydroxyamide amic acid) to poly(benzoxazole) via stepwise thermal cyclization: Structural changes and gas transport properties, Polymer, 52 (2011) 5127-5138.

[20] M.C. Duke, S.J. Pas, A.J. Hill, Y.S. Lin, J.C.D. da Costa, Exposing the molecular sieving architecture of amorphous silica using positron annihilation spectroscopy, Adv. Funct. Mater. 18 (2008) 3818-3826.

[21] C.-H. Lo, K.-S. Liao, W.-S. Hung, M. De Guzman, C.-C.Hu, K.-R. Lee, J.-Y. Lai, Investigation on positron annihilation characteristics of $\mathrm{CO}_{2}$-exposed zeolite, Micropor. Mesopor. Mat. 141 (2011) 140-145.

[22] A. Cabral-Prieto, I. Garcia-Sosa, R. Lopez-Castanares, O. Olea-Cardoso, Positronium annihilation in LTA-type zeolite, Micropor. Mesopor. Mater. 175 (2013) 134-140.

[23] S. Li, J.N. Sun, Z.J. Li, H.G. Peng, D. Gidley, E.T. Ryan, Y.S. Yan, Evaluation of pore structure in pure silica zeolite MFI low-k thin films using positronium annihilation lifetime spectroscopy, J. Phys. Chem. B. 108 (2004) 11689-11692.

[24] B. Zhu, C.M. Doherty, X.R. Xu, A.J. Hill, L.D. Zou, Y.S. Lin, M. Duke, Designing hierarchical porous features of ZSM-5 zeolites via $\mathrm{Si} / \mathrm{Al}$ ratio and their dynamic behavior in seawater ion complexes, Micropor. Mesopor. Mat. 173 (2013) 78-85.

[25] B. Zhu, L. D. Zou, C.M. Doherty, A.J. Hill, Y.S. Lin, X.R. Hu, H.T. Wang, M. Duke, Investigation of the effects of ion and water interaction on structure and chemistry of silicalite MFI type zeolite for its potential use as a seawater desalination membrane, J. Mater. Chem. 20 (2010) 4675-4683. 
[26] H.M. Chen, W.-S. Hung, C.-H. Lo, S.-H. Huang, M.-L. Cheng, G. Liu, K.-R. Lee, J.-Y. Lai, Y.-M. Sun, C.-C. Hu, R. Suzuki, T. Ohdaira, N. Oshima, Y.C. Jean, Free-volume depth profile of polymeric membranes studied by positron annihilation spectroscopy: Layer structure from interfacial polymerization, Macromolecules. 40 (2007) 7542-7557.

[27] S.-H. Huang, W.-S. Hung, D.-J. Liaw, C.-L. Li, S.-T. Kao, D.-M. Wang, M. De Guzman, C.-C. Hu, Y.C. Jean, K.-R. Lee, J.-Y. Lai, Investigation of multilayer pervaporation membrane by positron annihilation spectroscopy, Macromolecules. 41 (2008) 6438-6443.

[28] Y. C. Jean, H. M. Chen, S. Zhang, H. Z. Chen, L. J. Lee, S. Awad, J. Huang, C. H. Lau, H, Wang, F. Y. Li, T. S. Chung, Characterizing free volumes and layer structures in polymeric membranes using slow positron annihilation spectroscopy, J. Phys.: Conf. Ser. $262(2011) 1-9$.

[29] J. O'Brien-Abraham, M. Kanezashi. Y.S. Lin, A comparative study on permeation and mechanical properties of random and oriented MFI-type zeolite membranes, Micropor. Mesopor. Mater. 105 (2007) 140-148.

[30] H.B. Wang, Y.S. Lin, Synthesis and modification of ZSM-5/silicalite bilayer membrane with improved hydrogen separation performance, J. Membr. Sci. 396 (2012) 128-137.

[31] A. Gouzinis, M. Tsapatsis, On the preferred orientation and microstructural manipulation of molecular sieve films prepared by secondary growth, Chem. Mater. 10 (1998) 2497-2504.

[32] G. Xomeritakis, M. Tsapatsis, Permeation of aromatic isomer vapors through oriented MFI-Type membranes made by secondary growth, Chem. Mater. 11 (1999) 875-878.

[33] Y. C. Jean, P. E. Mallon, D. M. Schrader, Principles and applications of positron and positronium chemistry, World Scientific Publishing Co. Pte. Ltd., Singapore, 2003.

[34] S.J. Tao, Positronium annihilation in molecular substances, J. Chem. Phys. 56 (1972) 5499-5510.

[35] K. Ito, H. Nakanishi, Y. Ujihira, Extension of the equation for the annihilation lifetime of ortho-positronium at a cavity larger than $1 \mathrm{~nm}$ in radius, J. Phys. Chem. B 103 (1999) 4555-4558.

[36] P.J. Schultz, K.G. Lynn, Interaction of positron beams with surfaces, thin-films, and interfaces, Rev. Mod. Phys. 60 (1988) 701-779.

[37] G. Consolati, M. Mariani, R. Millini, F. Quasso, Investigation on the porosity of zeolite NU-88 by means of positron annihilation lifetime spectroscopy, Nucl. Instrum.Meth. B. 267 (2009) 2550-2553. 
[38] W.H. Yuan, Y.S. Lin, W.S. Yang, Molecular sieving MFI-Type zeolite membranes for pervaporation separation of xylene isomers, J. Am. Chem. Soc. 126 (2004) 4776-4777.

[39] J.H. Dong, Y.S. Lin, M.Z.C. Hu, R.A. Peascoe, E.A. Payzant, Template-removalassociated microstructural development of porous-ceramic-supported MFI zeolite membranes, Micropor. Mesopor. Mater. 34 (2000) 241-253. 
Table 1 Secondary growth conditions for MFI zeolite membranes

\begin{tabular}{ccccc}
\hline \multirow{2}{*}{ Membrane type } & \multicolumn{3}{c}{ Secondary growth conditions } \\
\cline { 3 - 5 } & $\begin{array}{c}\text { Structure and synthesis } \\
\text { method }\end{array}$ & $\begin{array}{c}\text { Temperature } \\
\left({ }^{\circ} \mathrm{C}\right)\end{array}$ & $\begin{array}{c}\text { Duration } \\
(\mathrm{h})\end{array}$ & $\begin{array}{c}\text { Number of } \\
\text { growths }\end{array}$ \\
\hline TR & $\begin{array}{c}\text { Ramdomly oriented with } \\
\text { template }\end{array}$ & 175 & 4 & 1 \\
TFR & $\begin{array}{c}\text { Randomly oriented } \\
\text { without template } \\
\text { hOh-oriented with } \\
\text { TH }\end{array}$ & 175 & 24 & 1 \\
tempalte & 130 & 24 & 2 \\
TC & $c$-oriented with template & 175 & 24 & 2 \\
\hline
\end{tabular}


Table 2 Positron lifetime results including lifetime, intensity, calculated pore radius and pore faction for TR, TFR, TH and TC membranes.

\begin{tabular}{|c|c|c|c|c|c|c|c|c|c|}
\hline \multirow{2}{*}{$\begin{array}{l}\text { Sample } \\
\text { name }\end{array}$} & \multirow[b]{2}{*}{ Synthesis method } & \multicolumn{2}{|c|}{ Lifetime (ns) } & \multicolumn{2}{|c|}{ Intensity (\%) } & \multicolumn{2}{|c|}{ Pore radius $(\AA)$} & \multicolumn{2}{|c|}{ Pore volume fraction $(\%)$} \\
\hline & & $\tau_{3}$ & $\tau_{4}$ & $\mathrm{I}_{3}$ & $\mathrm{I}_{4}$ & $\begin{array}{c}\text { Intracrystalline } \\
\left(\text { from } \tau_{3}\right)\end{array}$ & $\begin{array}{l}\text { Intercrystalline } \\
\left.\text { (from } \tau_{4}\right)\end{array}$ & $\begin{array}{c}\text { Intracrystalline } \\
\left(\mathrm{I}_{3} /\left(\mathrm{I}_{3}+\mathrm{I}_{4}\right)\right)\end{array}$ & $\begin{array}{c}\text { Intercrystalline } \\
\left(\mathrm{I}_{4} /\left(\mathrm{I}_{3}+\mathrm{I}_{4}\right)\right)\end{array}$ \\
\hline $\mathrm{TR}$ & $\begin{array}{l}\text { Templated synthesis, } \\
\text { randomly oriented }\end{array}$ & $2.30 \pm 0.02$ & $17.51 \pm 0.68$ & $38.36 \pm 0.38$ & $2.32 \pm 0.07$ & $3.11 \pm 0.01$ & $8.33 \pm 0.03$ & 94.3 & 5.7 \\
\hline TFR & $\begin{array}{c}\text { Template free synthesis, } \\
\text { randomly oriented }\end{array}$ & $2.22 \pm 0.02$ & $13.34 \pm 0.59$ & $32.56 \pm 0.28$ & $1.56 \pm 0.07$ & $3.05 \pm 0.01$ & $7.43 \pm 0.04$ & 95.4 & 4.6 \\
\hline TH & $\begin{array}{c}\text { Templated synthesis, } \\
\text { h0h-oriented }\end{array}$ & $3.01 \pm 0.02$ & $16.05 \pm 0.44$ & $38.26 \pm 0.23$ & $3.48 \pm 0.10$ & $3.64 \pm 0.01$ & $8.04 \pm 0.02$ & 91.7 & 8.3 \\
\hline $\mathrm{TC}$ & $\begin{array}{c}\text { Templated synthesis, } c- \\
\text { oriented }\end{array}$ & $1.87 \pm 0.05$ & $22.11 \pm 0.16$ & $16.17 \pm 0.69$ & $18.45 \pm 0.09$ & $2.73 \pm 0.04$ & $9.17 \pm 0.01$ & 46.7 & 53.3 \\
\hline
\end{tabular}


Table 3 Pervaporation separation results of single component $p$-xylene and $o$-xylene at room temperature for TR, TFR, TH and TC membranes.

\begin{tabular}{cccc}
\hline Membranes & $\begin{array}{c}p \text {-xylene flux } \\
\left(\mathrm{kg} / \mathrm{m}^{2} \cdot \mathrm{hr}\right)\end{array}$ & $\begin{array}{c}o \text {-xylene flux } \\
\left(\mathrm{kg} / \mathrm{m}^{2} \cdot \mathrm{hr}\right)\end{array}$ & $\begin{array}{c}p / o \text {-xylene } \\
\text { ideal selectivity }\end{array}$ \\
\hline TR & 0.71 & 0.39 & 1.8 \\
TFR & 0.17 & 0.007 & 24 \\
TH & 0.24 & 0.10 & 2.4 \\
TC & 0.22 & 0.06 & 3.6 \\
\hline
\end{tabular}




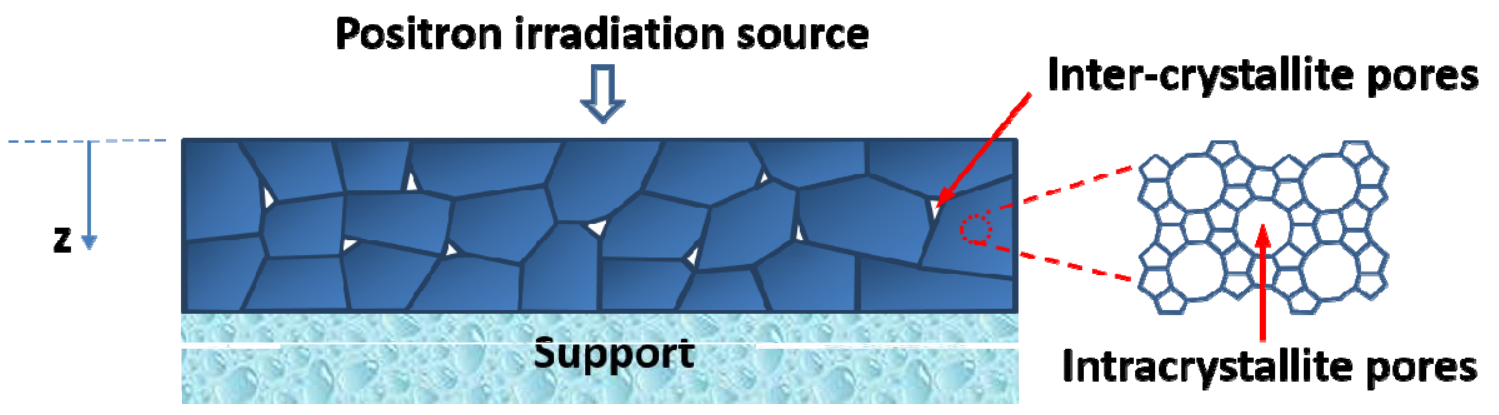

Fig. 1. Schematics of the transport of positrons in a polycystalline MFI zeolite membrane. 


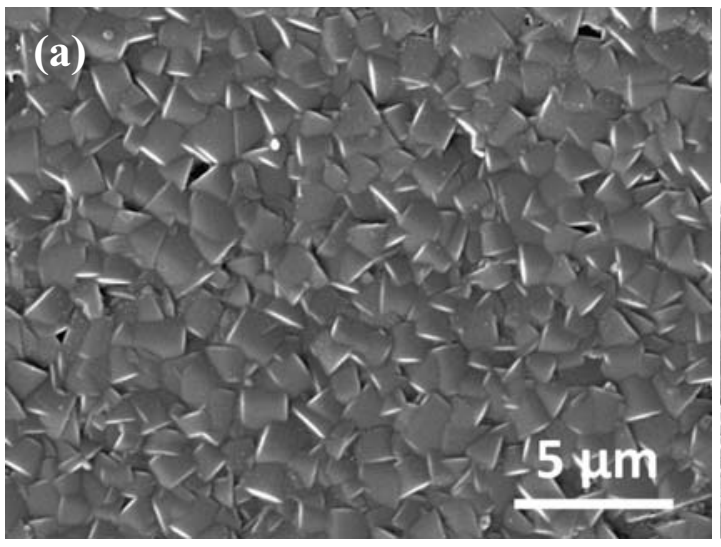

(b)
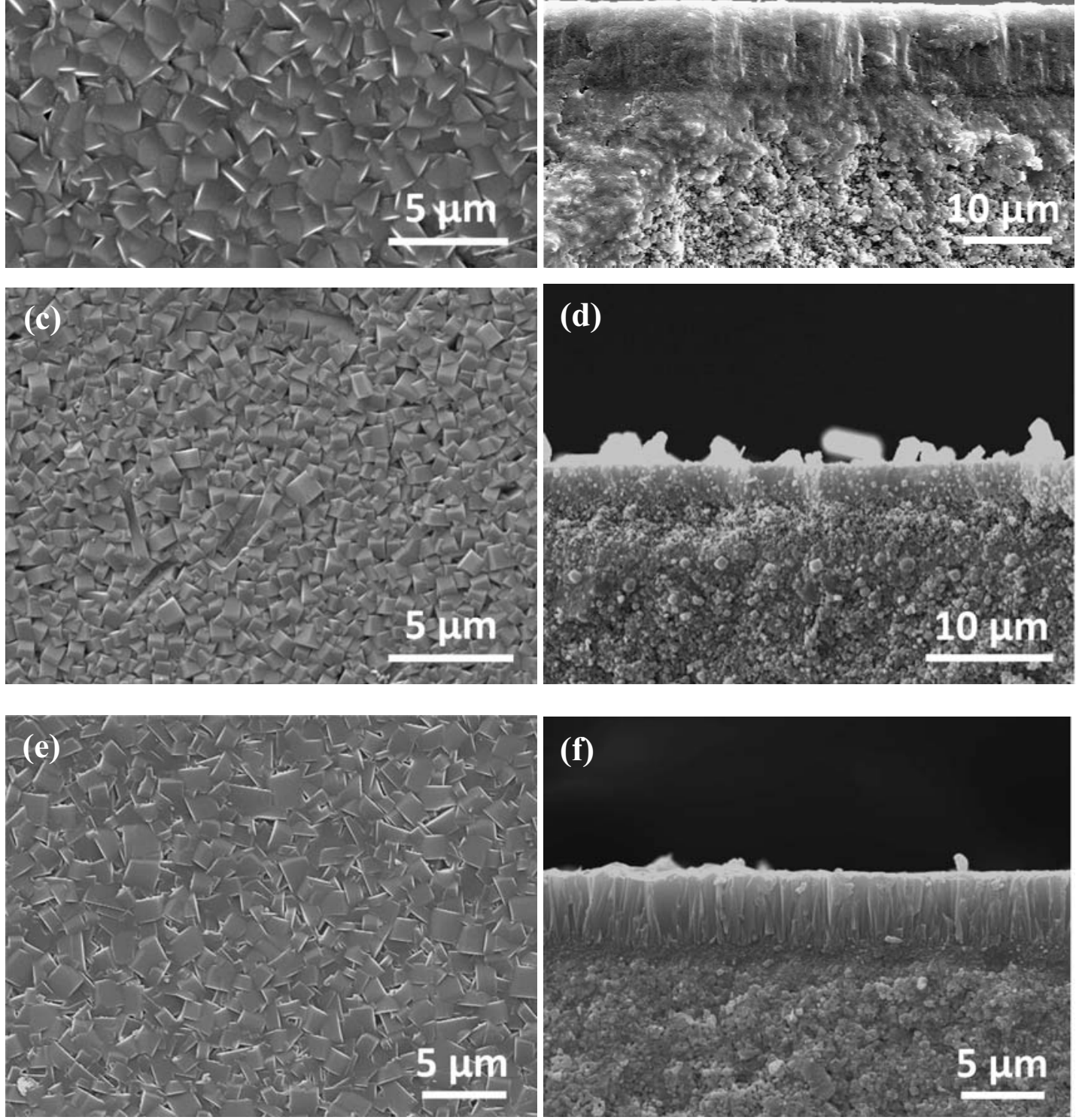

(d)
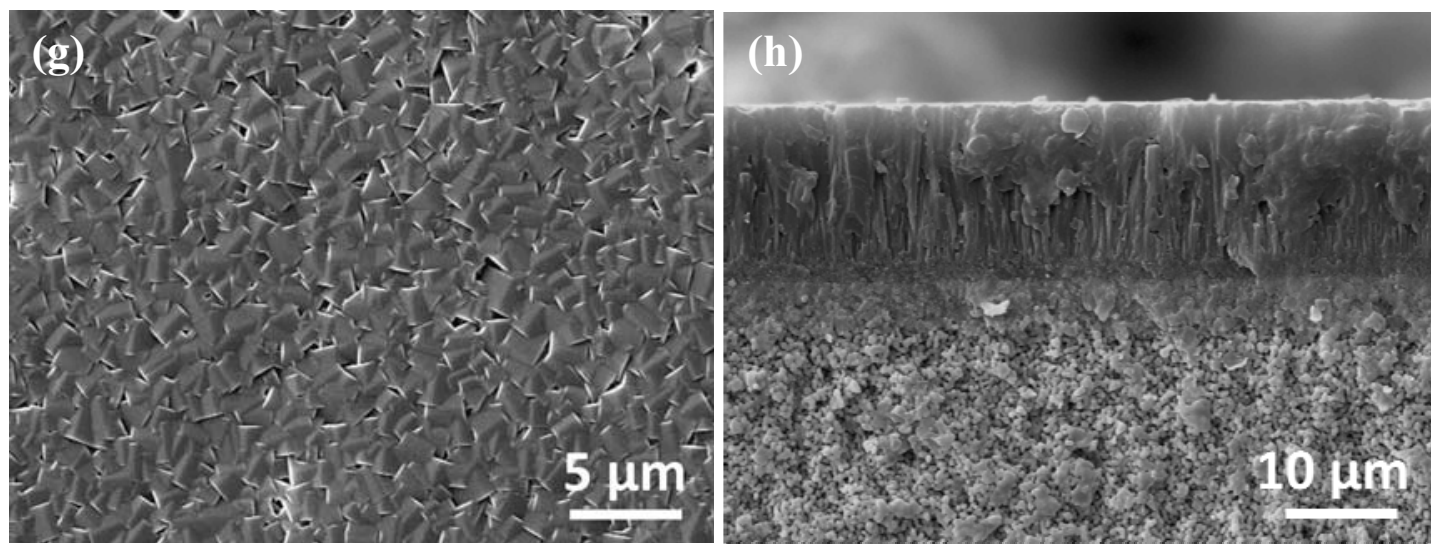
Fig. 2. Surface and cross-section SEM images of $(a, b)$ templated synthesized random oriented MFI membrane (TR), (c, d) template free synthesized random oriented MFI membrane (TFR), (e, f) templated synthesized $h 0 h$-oriented MFI membrane (TH), and (g, h) templated synthesized $c$-oriented MFI membrane (TC). 


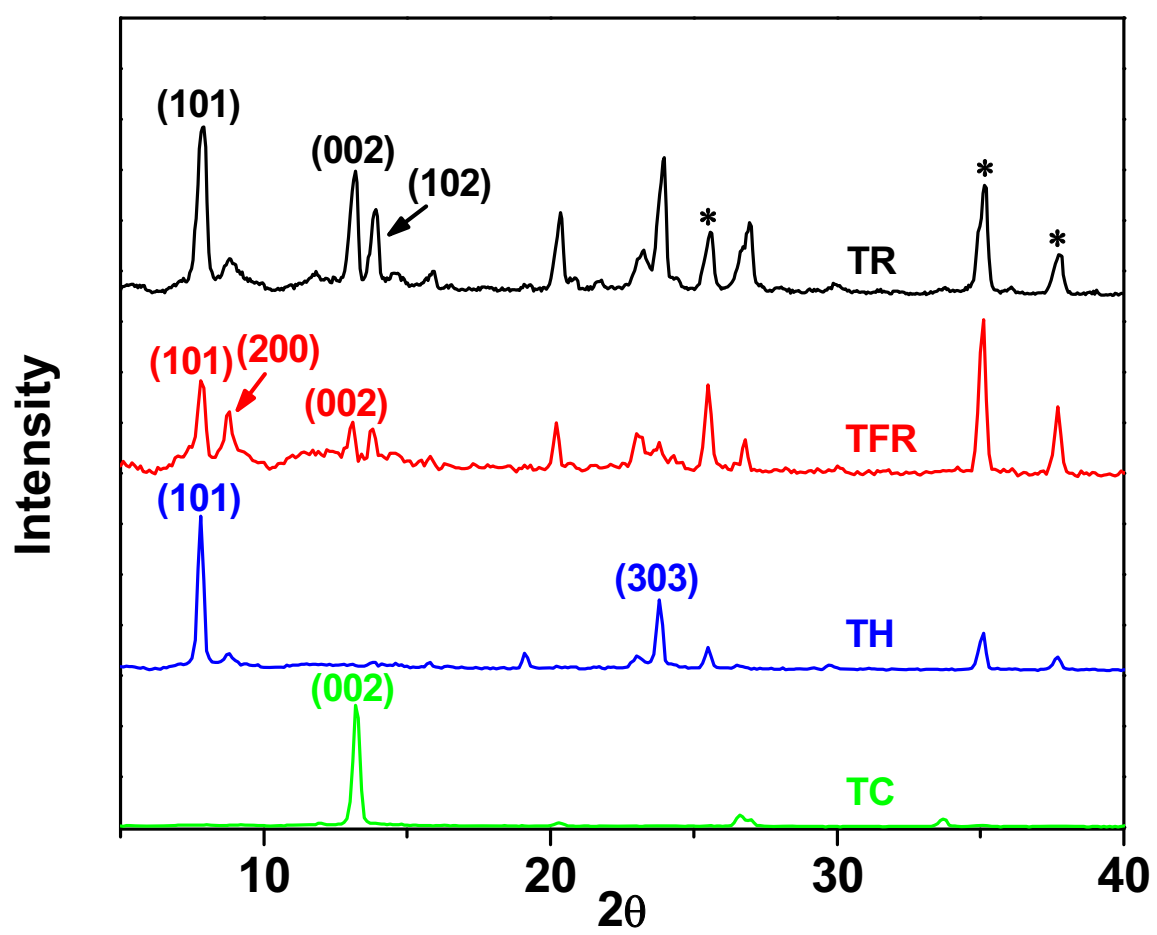

Fig. 3. XRD patterns of templated synthesized random oriented MFI membrane (TR), template free synthesized random oriented MFI membrane (TFR), templated synthesized $h 0 h$-oriented MFI membrane (TH), and templated synthesized $c$-oriented MFI membrane (TC). The asterisks * in the XRD spectra indicate the peaks of alumina substrate. 


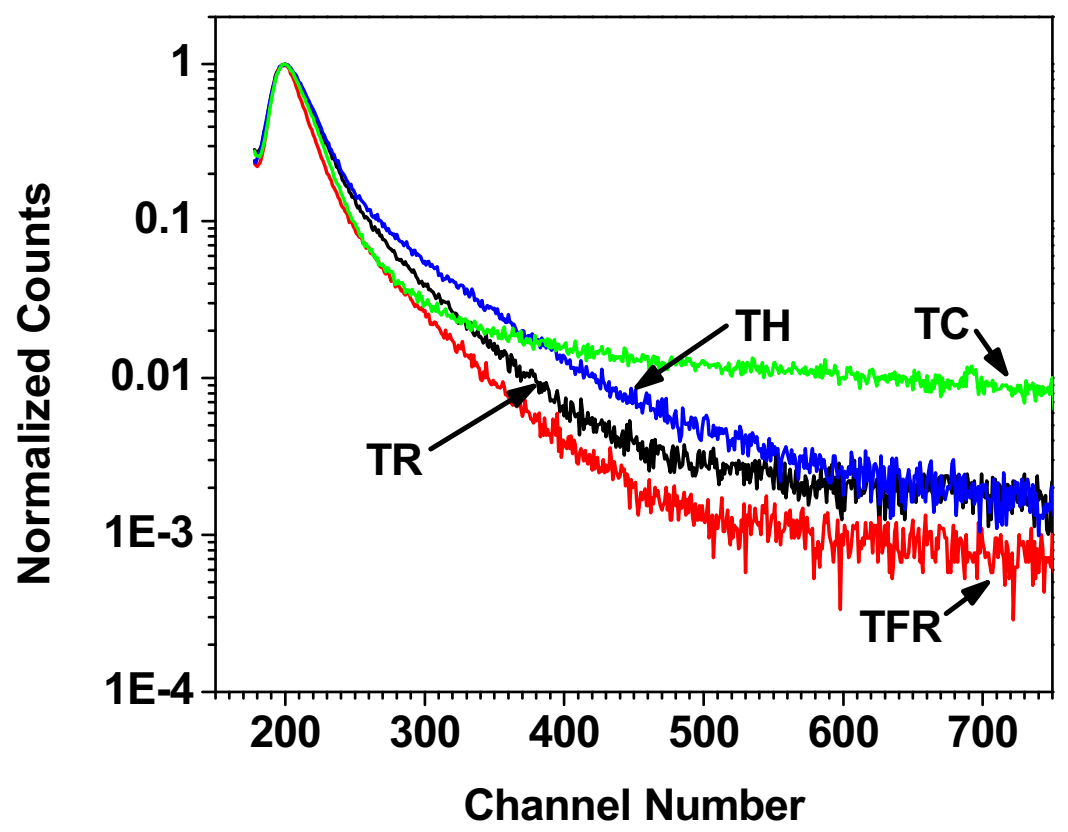

Fig. 4. Normalized positron annihilation lifetime spectra for TR, TFR, TH and TC MFI-type zeolite membranes. 


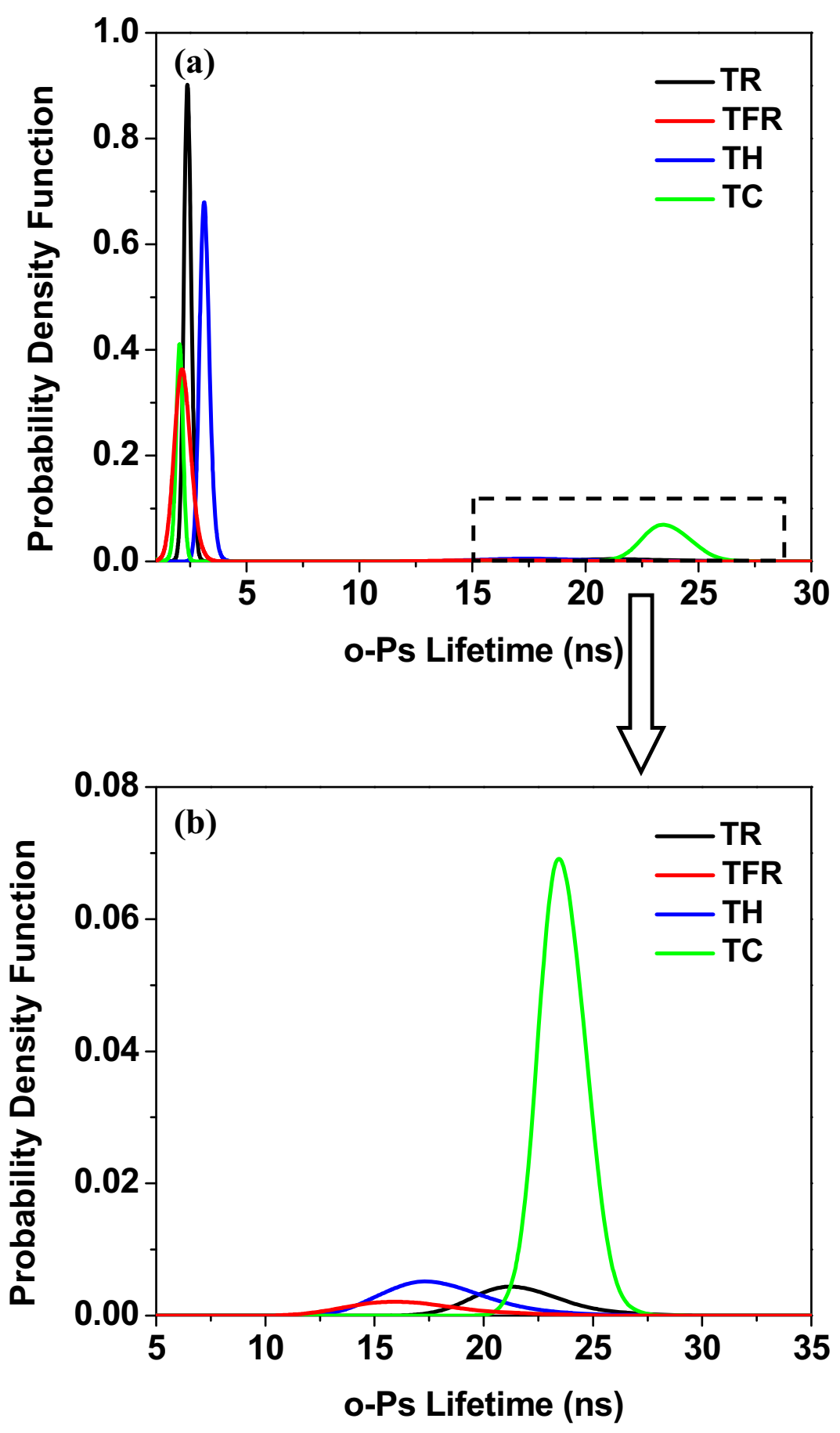

Fig. 5. (a) Distribution curves of o-Ps with lifetime in the range from 1 to $30 \mathrm{~ns}$ representing all the micropores in the four membranes, (b) Enlarged distribution curves of o-Ps with longer lifetime in the range from 5 to $35 \mathrm{~ns}$ representing the larger micropores (intercrystalline micropores) in the four membranes. 

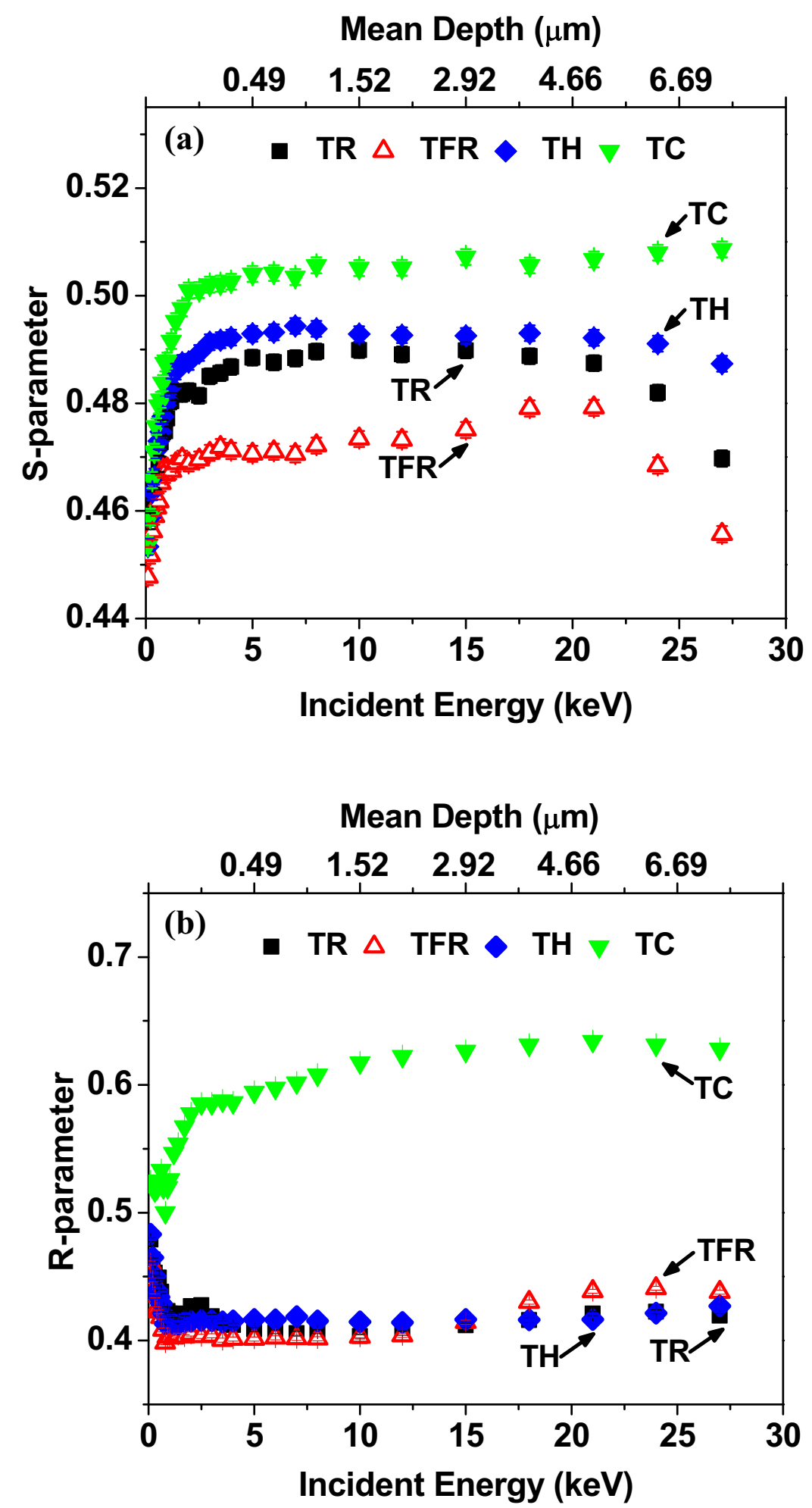

Fig. 6. (a) S parameters vs positron incident energy and depth, and (b) R parameters vs positron incident energy and depth for TR, TFR, TH, and TC MFI-type zeolite membranes. 

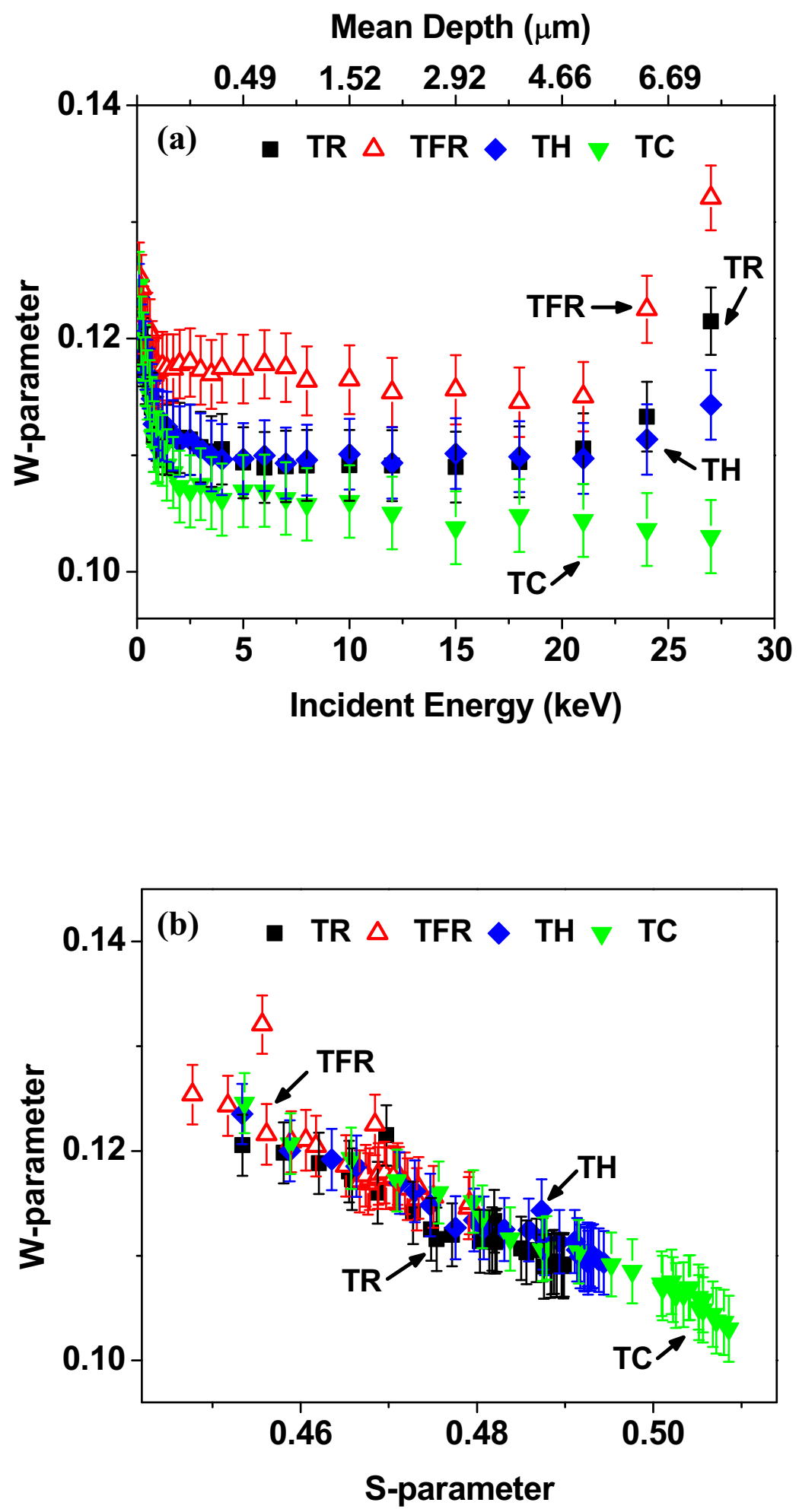

Fig. 7. (a) W parameters vs positron incident energy and depth, (b) W parameters vs $\mathrm{S}$ parameters for TR, TFR, TH, and TC MFI-type zeolite membranes. 
(a)
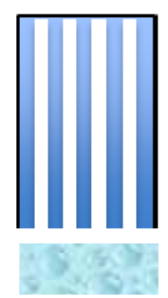

Intercrystallne pores
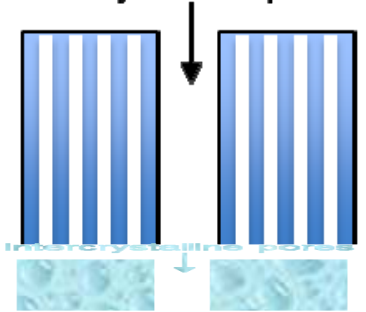

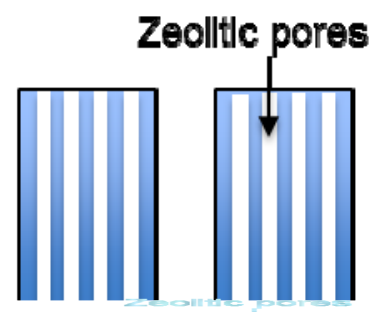

1):5.5.

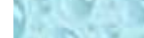

Randomly or hoh-orlented membrane, templated

(b) Intercrystalline pores Zeolltic pores

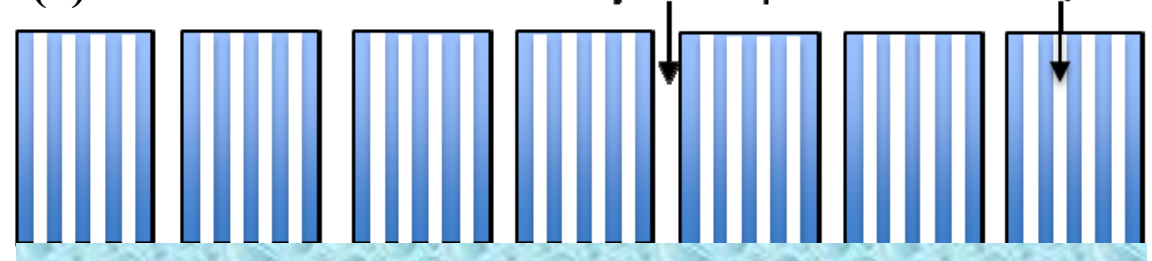

Randomly orlented membrane, template-free

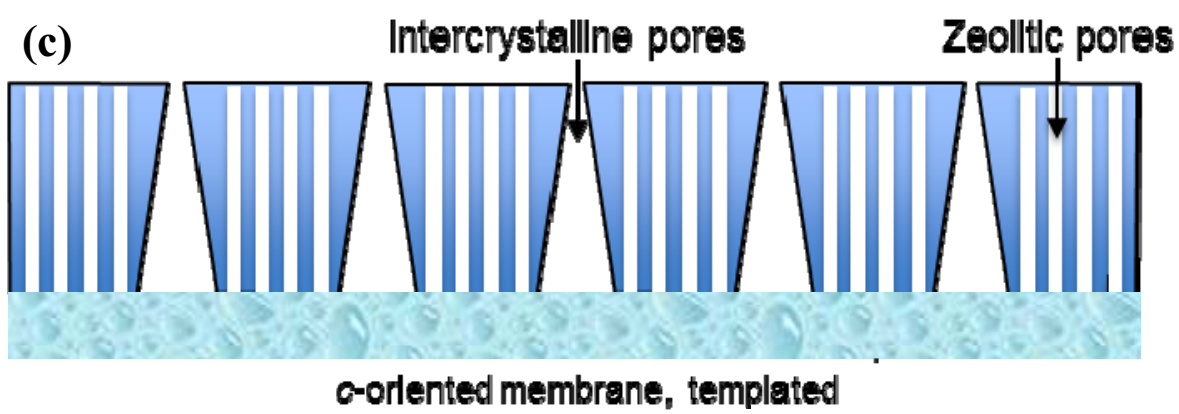

Fig. 8. Schematic showing three types of microstructure of MFI zeolite membranes: (a) Templated synthesized random and $h 0 h$-oriented MFI membranes (TR and TH) containing a moderate amount of intercrystalline micropores with medium pore size, (b) Template-free synthesized MFI membrane (TFR) containing a small amount of intercrystalline micropores with smaller pore size, and (c) Templated synthesized $c$-oriented MFI membrane with substantially larger amount of large intercrystalline pores. 


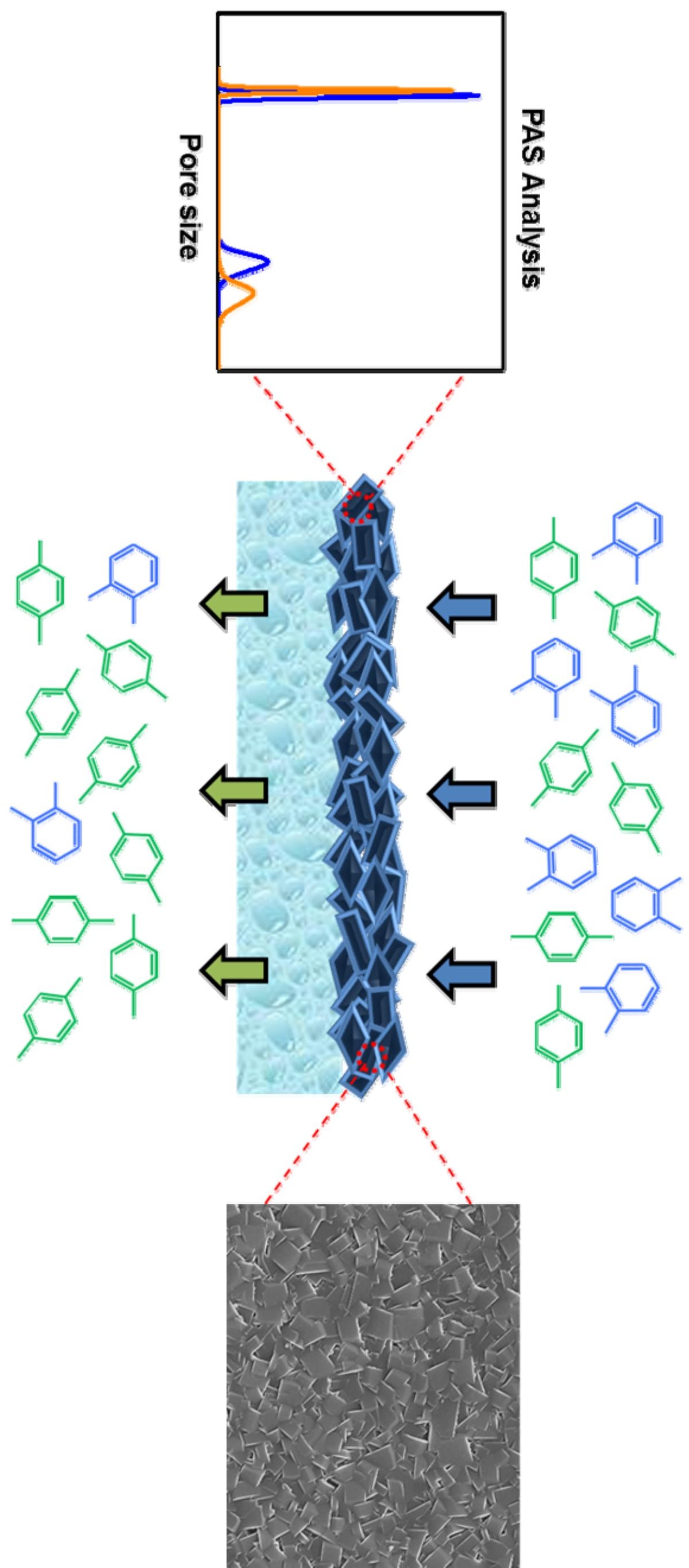

